\title{
Complexity Drivers in Digitalized Work Systems: Implications for Cooperative Forms of Work
}

\author{
Benedikt Andrew Latos*, Markus Harlacher*, Florens Burgert, Verena Nitsch, Philipp Przybysz, Susanne Mütze-Niewöhner \\ Institute of Industrial Engineering and Ergonomics, Work Organization Department, RWTH Aachen University,
}

52062 Aachen, Germany

\begin{tabular}{l} 
A R T I C L E I N F O \\
\hline Article history: \\
Received: 01 August, 2018 \\
Accepted: 16 September, 201 \\
Online: 27 September, 2018 \\
\hline Keywords: \\
complexity \\
digitalization \\
work organization \\
cooperative forms of work
\end{tabular}

\section{Introduction}

This article is an extension of work originally presented on the IEEE International Conference on Industrial Engineering \& Engineering Management in Singapore (December 2017) [1].

Digitalization considerably affects work systems through diverse and quicker communication media as well as through the networking of manufacturing facilities and information systems. Industry 4.0, or the concept of advanced manufacturing, is used to manufacture individualized consumer goods or machines that are progressively equipped with mechatronic components [2]. Also, developments towards dynamic customer requirements change production planning for these products, since personalized customer requirements necessitate real-time and flexible reactions within a company [3]. This causes an increase in complexity in the process organization. According to [4], [5], though, the use of digital systems is able to reduce complexity in production planning, as they enable a more efficient and flexible control and management of company processes. However, the use of digital

\footnotetext{
* Benedikt Andrew Latos, Markus Harlacher; Bergdriesch 27, 52062 Aachen,
} Germany, b.latos@iaw.rwth-aachen.de; m.harlacher@iaw.rwth-aachen.de systems may cause interface problems or media discontinuities due to missing IT standards, since different IT systems are used for data acquisition that are not compatible with each other [6]. Yet, digitalization also enables the introduction of internal and external company network structures so that distributed and global cooperation across company boundaries is feasible [7]. Another significant change in the course of digitalization, which is discussed in literature, is the increase in the decision-making powers for employees that also partly results from flatter hierarchies [8], [9]. There is a general trend towards decentralized forms of management and control [10]. This implies that team and group work or interaction between individuals (in this article the term "cooperative forms of work" is employed) is relevant especially in the course of digitalization. The changes result in an increase in the demands on employees. On the one hand, social competences are required. On the other hand, IT-related knowledge and skills in particular are becoming more important because digital technologies are used in almost all areas of companies and therefore must be handled by the employees [6], [9], [11], [12]. 


\section{B. A. Latos et al. / Advances in Science, Technology and Engineering Systems Journal Vol. 3, No. 5, 166-185 (2018)}

As all these facets might cause levels of higher complexity, it is important to install appropriate complexity management procedures in highly digitalized labor environments [13]. In order to manage complexity, it is necessary to understand the causes of complexity and its relationships, and to keep in mind that complexity may have both positive and negative effects.

This article investigates how the digital transformation relates to complexity in work environments. It examines work systems that use information and communication technologies which are interconnected to a large extent and are increasingly mobile as well as systems that process and supply significant proportions of information in digital forms (cf. [14]). Current complexity definitions from relevant research fields do not entirely incorporate important complexity characteristics with respect to a work system. Therefore, a framework for work systems is employed to systematize and analyze existing complexity definitions (section 2 ). Moreover, there is a lack of suitable classification systems for complexity drivers in digitalized work systems. In order to systematize complexity drivers that are explored with 23 semistructured expert interviews (section 3), six organizational dimensions are chosen as a framework to present the results (section 4). Subsequently, complexity management approaches in digitalized work systems are outlined and digitalization-related effects on cooperative forms of work are discussed (section 5). The individual task complexity concept of Dalhöfer and Prieß [15] is extended to consider a work group. The article concludes with a critical discussion of the findings and outlines future research steps (section 6).

\section{Complexity definitions from different research disciplines}

The expression complex is widely employed in everyday language to express the difficulty of comprehending, investigating and forecasting relationships or systems' behavior that is not easy to understand. In research, the use and understanding of complexity depend on the specific research discipline [13], [16], [17], [18]. In order to conceptualize actions to handle complexity in digitalized work systems, it is vital to develop a theoretically grounded approach. Therefore, it is necessary to systematize existing definitions of complexity from relevant research disciplines in a framework that is suitable to represent a work system. As a basis for this framework the general model of a work system according to Schlick et al. [19] was chosen. This model describes the transformation process of input variables inside the work system into outputs. The working person that executes this transformation with work equipment is an essential part of the work system. Relevant research disciplines from the pluri- and interdisciplinary research field of industrial engineering and ergonomics that consider work system design are in particular: engineering, economics, sociology, and industrial and organizational psychology (see e.g. [19]). In order to develop an understanding of complexity for this framework, the understanding of complexity within these research disciplines is examined below:

Although diverse scientific disciplines employ the expression complexity in different manners, general system theory is widely used to define the phenomenon of complexity [16]. Since a work system can be regarded as a general system, the characteristics of complex systems are outlined: systems that are meant to be complex have lots of system elements as well as they exhibit many interactions simultaneously [20][21]. Relevant literature on system theory indicates that certain characteristics of complex systems are the number and type of elements and interactions, rate of change of the system structure and uncertainty of the current and future system status (various complexity definitions can be found e.g. in [16][22]). In fact, von Bertalanffy [23] states that the characteristics of a system are due to the properties of its elements and the connections amongst them. The construct of emergence is special for complex systems. This phenomenon means that the system's behavior is not entirely explainable with the properties of the single system elements [24]. Schuh and Schwenk [25] distinguish between simple, complicated, relatively complex and extremely complex systems, based on their number and diversity of the elements and relations as well as their variability and dynamic (see Figure 1). Whilst simple systems are characterized by few elements, interrelations and behavioral possibilities, extremely complex systems have a multitude of elements with a great variety of interrelations and possible system behaviors with variable impacts of the elements [26].

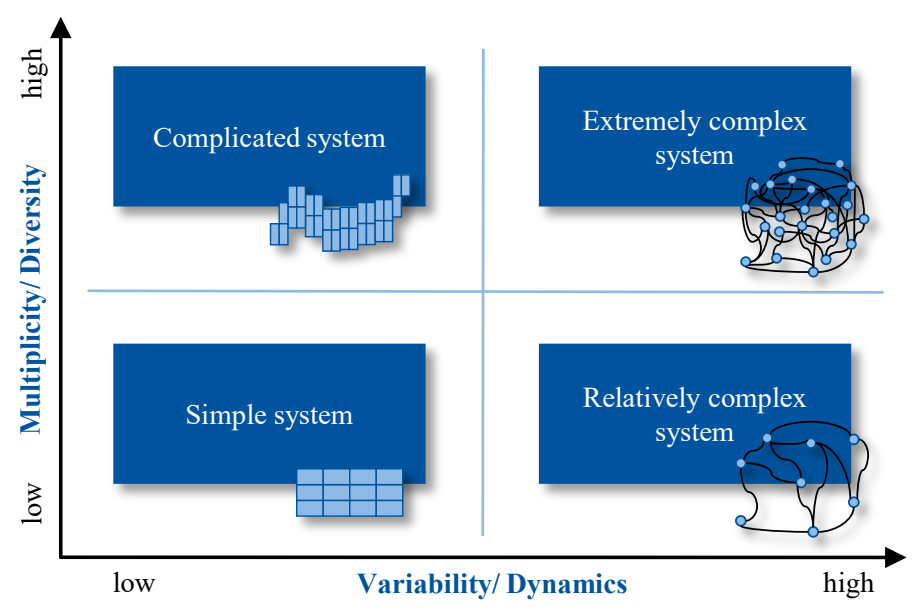

Figure 1: System states according to Schuh and Schwenk [25], Ulrich and Probst [26]

System theory is also frequently used in engineering disciplines to explain the phenomenon of complexity. Therefore, the complexity properties from general system theory also apply to considerations of complexity in an engineering context [27], [28], [29]. For example, system elements in a labor system are produced goods, tools, assignments or personnel. The system's interrelations are, for instance, relationships of the elements during production or communication procedures. Because digitalization in work systems could have an impact on the elements or relationships in the system, this could also change the level of complexity in it.

In the literature, researchers distinguish static or structural complexity from dynamic or operational complexity when manufacturing systems are regarded [27]. The two facets are often generalized as objective complexity, whereas Blockus [22] describes complexity in the field of business administration with reference to system theory and includes perception as a subjective complexity characteristic. This aspect is crucial for a work system framework, since workers operate in these systems. For production systems, subjective complexity reflects how individual persons 


\section{B. A. Latos et al. / Advances in Science, Technology and Engineering Systems Journal Vol. 3, No. 5, 166-185 (2018)}

experience complexity, e.g. with respect to the design of single work stations in assembly [30]. Zeltzer et al. [31] state that complexity perception in assembly is largely determined by the operator and therefore define complexity as subjectively negative perceived effects of the assembly system on the operator.

Persons in work systems have to make numerous decisions whilst performing their jobs. This is why the complexity understanding in psychology is important for the framework. Within the discipline of psychology, complex situations and problems are described by interrelated variables, a considerable level of dynamics, a lack of transparency concerning a situation and multiple goals that are conflicting (polytely) [32][33][34]. Willke [35] provides a sociological definition that considers the degree of multidimensionality, interconnectedness and relevance of the consequences of a decision problem. Complex systems have diverse options that can be chosen so that operators have to select an alternative [36].

The aforementioned complexity definitions contain central characteristics, which are relevant for a complexity definition with regard to a work system. For a systematic comparative analysis of existing complexity definitions, which relate to the chosen framework, relevant criteria are required:
In this article, work systems are considered with regard to the transformation of work through digitalization. Therefore, a system-theoretic criterion "system size" should be defined that considers the type and number of elements, as well as interactions between them. As second criterion, "dynamics and uncertainty" should be included. This criterion considers the non-static and emergent behavior of complex systems. Concerning the work system framework, the system-theoretical concept should be expanded to consider humans and effects of working conditions on humans. Decision behavior of human operators in complex situations within their work systems should be taken into account. Therefore, "polytely" is defined as a criterion for complex situations with conflicting goals. In addition, complexity may arise due to human information processing and differing semantic perceptions. Following the stress-strain-concept [37][38] and the individual perception of complexity according to Blockus [22], it has to be stated that human perception of complexity is subjective. Thus, the criterion "subjectivity" is introduced. With respect to the transformation of work through digitalization, the aspect "digitalization" is explicitly included. Figure 2 presents a selection of complexity definitions from relevant research disciplines with regard to the derived criteria.

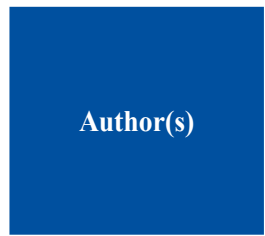

von Bertalanffy (1972)

Ulrich and Probst (1988)

Deshmukh et al. (1998)

Sivadasan et al. (2006)

Blockus (2010)

Zeltzer et al. (2013)

Dörner et al. (1983), Dörner (2011), Kluge (2004)

Willke (1996)

Luhmann (1991)
Sociology

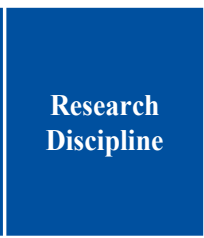

System theory

System theory

Engineering

Engineering

Business Administration

Engineering (assembly system design)

Psychology

Sociology

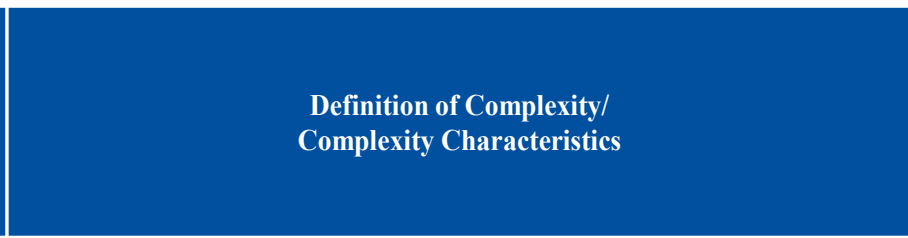

Number of elements, variety of elements, number of interrelations

Complex systems are characterized by a high number and diversity of the elements and relations as well as high variability and dynamics. This allows complex systems to be distinguished from simple and complicated systems.

Static complexity of a production system is characterized by its structure, variety of subsystems and strength of the interactions.

The dynamic or operational complexity is defined as uncertainty regarding the temporal change of the system.

The main characteristics are the number and type of elements and connections and the variability over time. Beside these objective complexity characteristics, perception is considered as a subjective component.
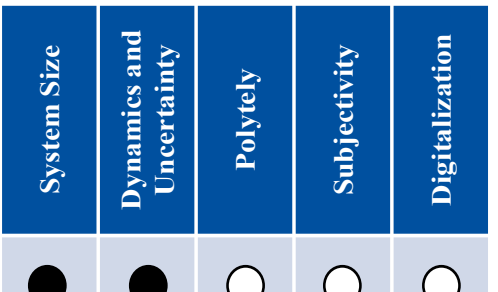

Complexity of a workstation is the sum of all technical and ergonomical aspects and factors that make the set of tasks to be performed within it by an operator mentally difficult, error-prone, requiring thinking and vigilance, and inducing stress.

A complex problem is described by four characteristics: dependencies between variables, internal dynamics, non-transparency of the situation, multiple conflicting goals (polytely).
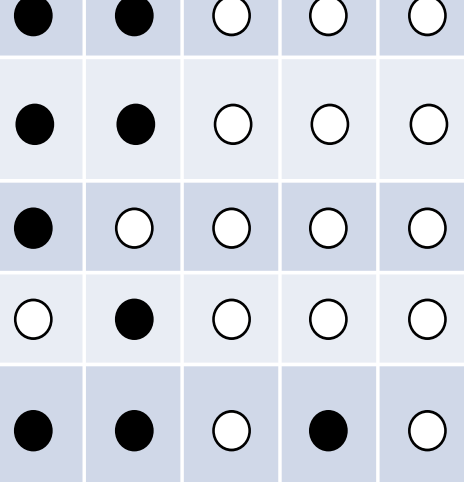

Complexity is described by three characteristics: multidimensionality, interconnectedness and relevance of the consequences of a decision problem.

A system is complicated with a large number of elements and connections, whereby a complex system simultaneously contains many alternative options and forces selection.

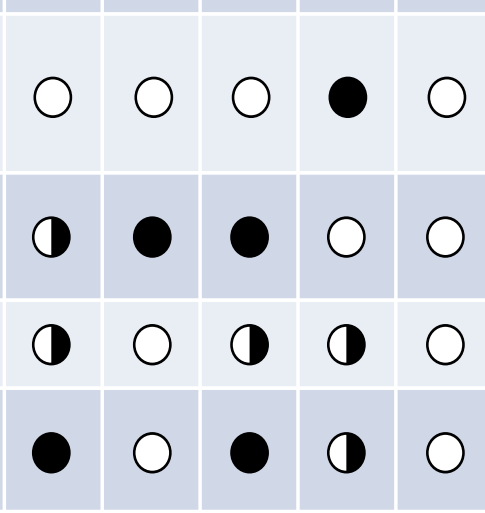

Explanation for evaluation criteria: $\bigcirc$ fulfilled; $\bigcirc$ partially fulfilled; $\bigcirc$ not fulfilled 


\section{B. A. Latos et al. / Advances in Science, Technology and Engineering Systems Journal Vol. 3, No. 5, 166-185 (2018)}

The results illustrate that none of the considered definitions fully covers all defined criteria. Striving towards a definition containing all criteria, a synthesis of the discipline-specific definitions is required. Additionally, none of the definitions includes the aspect of digitalization. As a conclusion, the findings can be used to derive an integrated comprehension of complexity characteristics in the context of digitalized work systems:

- Complexity in a system refers to a construct of higher order that is composed of single system elements.

- A complex system, as sum of its elements, has the properties of high dynamics caused by multidimensional interactions, unpredictability of the system state and polytely, inducing self-generated characteristics of the system.

- Concerning the digitalization of work systems, objective complexity has to be distinguished from subjective complexity. While subjective complexity is induced by information processing and perception of the individual, objective complexity arises from interactions of internal system relations and external environmental impacts.

Especially from a work design point of view, it is crucial to develop a deep comprehension of variables that induce complexity in a digitalized work environment. On the one hand, labor systems with a too high degree of complexity are avoidable. On the other hand, operators may be qualified to manage complexity, if they are provided with sufficient information via support systems within work procedures. Moreover, complexity is also mentioned in terms of knowledge management as a basis for developing flexible and self-learning organizational structures [39]. All these aspects can only be considered, if there is a fundamental knowledge of complexity drivers in a work system. In this article, the understanding of the term "complexity driver" is based on the general definition of Vogel and Lasch [40], which they developed from the use of the term in the literature:

"Complexity drivers are factors, which influence a system's complexity and company's target achievement. They are responsible for increasing system's [sic] complexity level and help to define the characteristics or the phenomenon of a system's complexity. Complexity drivers are influenced by one another, that is by internal or external drivers, and cannot be reduced completely to another one" ([40], p. 18).

As another result of their systematic literature research, Vogel and Lasch [40] show that there is a multitude of different approaches to identify and classify complexity drivers. They identify complexity drivers with a systematic literature research procedure and employ a quantitative frequency analysis of mentioned complexity drivers. They present a general complexity driver classification system, based on existing classification systems, which is shown in Figure 3.

External complexity drivers are distinguished from internal and general complexity. The internal complexity can be actively influenced by the company. It is further divided into correlated complexity drivers, which are directly related to external complexity impacts, and autonomous complexity drivers, which are not directly influenced by external impacts. The general complexity category includes all drivers that cannot directly be assigned to other specific categories (e.g. uncertainty). The rectangles in Figure 3 represent one complexity driver category that is further subdivided into numerous complexity drivers. Detailed descriptions of the assigned complexity drivers are presented in [40].

However, it can be seen that digitalization is not explicitly included as a complexity driving factor. This also applies to alternative complexity driver systematizations (see e.g. [41][42][43][44]). Furthermore, diverse methods exist in order to assess the level of complexity in work systems (see e.g. [41][42][45]). However, these approaches also do not explicitly take changes into account that are caused through digitalization.

Above all, these classification systems regard complexity on a general or company-wide level. They do not focus on complexity drivers that directly relate to work of the persons in a company and their specific work systems. This necessitates that a suitable framework has to be used to explore drivers of complexity in digitalized work systems. This framework is presented in the next section.

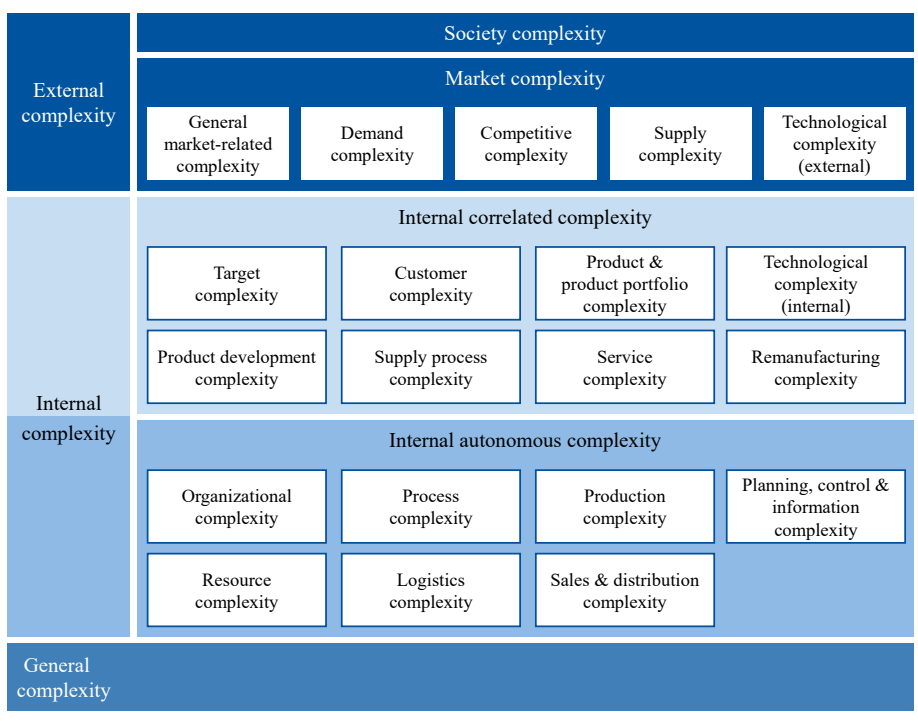

[40]

\section{Methodology}

As a framework to systematize drivers of complexity in digitalized work systems, six organizational dimensions were chosen. The organizational dimensions were the process organization, organizational structure, technology, working conditions, product and personnel. The authors have employed this framework already in diverse transformation projects in different industry sectors. In these projects, the dimensions have proven to be applicable for holistic organizational transformation projects regardless of industry settings.

To identify drivers of complexity for every organizational dimension in digitalized work systems, semi-structured expert interviews were performed. This methodology was selected, because it provides valuable qualitative insights at an initial exploration stage. Moreover, it can be used to complement ongoing quantitative research steps. The questions consisted of a constant number of open questions. This procedure guaranteed that 


\section{B. A. Latos et al. / Advances in Science, Technology and Engineering Systems Journal Vol. 3, No. 5, 166-185 (2018)}

all important questions were treated in all interview sessions. However, the interview design made it possible to stress on aspects that are especially important for an individual interviewee at the same time. Also, the aspects could be discussed according to the individual reference framework. The duration of the interviews was about 45 minutes. The interviews were transcribed according to Mayring [46] by using the audio recordings with permission of the interviewees. In one case, no recording was available so that interview notes were used. The interview transcription time took up to 8 hours for one interview. In total, 23 interviews were performed. 22 interviews were conducted via phone. One was a personal interview. The majority was conducted as phone interviews because of interview economics reasons: the interviewees worked in companies that are spread throughout Germany. Figure 4 gives an overview on the experts and their backgrounds that were included in the study. The interviewees were acquired via using the databases and business networks of the research institute. They were requested via e-mail. In total, about 30 interview requests were sent, whereof 23 interviewees accepted the invitation. For being taken into account as an expert, two requirements had to be fulfilled: the experts needed to have privileged access to information and must have been responsible for conceptualizing, implementing or controlling problem solutions with regard to digital strategies [47].

The 23 interviewees held positions in German academia or industry and were requested because of their positions and knowledge of digitalization and complexity management or their expertise of work organization. Moreover, the experts belonged to industries from both production and service. Most worked in the fields of engineering, the management of projects, consignment and logistics, information and communication technology, banking or within the media industry.

Also, the experts were representatives of entrepreneurs or belonged to committees that represent employees. To prevent biased analysis results, the expert acquisition procedure was conducted in a manner to obtain interviewees that cover several domains and stakeholder groups.

\begin{tabular}{|c|c|c|c|c|}
\hline Number & Sectors / Domains & Function of the expert & Comment & $\begin{array}{l}\text { Number of } \\
\text { employees }\end{array}$ \\
\hline 1 & System house & Director of system house & $\begin{array}{l}\text { Development and consulting of IT system houses } \\
\text { (focus on process organization) }\end{array}$ & $<50$ \\
\hline 2 & Science & Professor information management & Focus on hybrid services, digital business models & $<50$ \\
\hline 3 & White goods & Head of Department assembly & Cycled assembly system (large quantity) & $>10,000$ \\
\hline 4 & Software company & Customer adviser product lifecycle management & Cloud computing, Big Data analysis & $>1,000$ \\
\hline 5 & White goods & Head of Department industrial engineering & $\begin{array}{l}\text { Digital assistance systems with work instructions, } \\
\text { error feedback via apps }\end{array}$ & $>10,000$ \\
\hline 6 & Automotive & Expert industry 4.0 in corporate work council & Focus on digital work, industry 4.0 & $>100,000$ \\
\hline 7 & Start-up electro mobility & Chief information officer & $\begin{array}{l}\text { Agile, digital product development, smart products in } \\
\text { the automotive sector }\end{array}$ & $<250$ \\
\hline 8 & Science & Director of demonstration factory & Demonstration Factory Industry 4.0 & $<250$ \\
\hline 9 & Science & Expert industry 4.0 & $\begin{array}{l}\text { Holistic production and enterprise system design, } \\
\text { project management }\end{array}$ & $<250$ \\
\hline 10 & Logistics, consignment & Chief executive officer & System solutions for working with smart glasses & $<50$ \\
\hline 11 & Industrial Connectivity & $\begin{array}{l}\text { Head of Department global digitalization and } \\
\text { intelligence }\end{array}$ & Data connection of world-wide facilities & $>1,000$ \\
\hline 12 & Automotive & Complexity manager & Focus on the use of digital analysis methods & $>50,000$ \\
\hline 13 & $\begin{array}{l}\text { Service, maintenance and } \\
\text { repair }\end{array}$ & Key account manager & Proactive maintenance through the use of digital tools & $>1,000$ \\
\hline 14 & Consulting and research & Director of consulting company & Enterprise organization & $<50$ \\
\hline 15 & Media & Chairperson of work council & Print media & $>1,000$ \\
\hline 16 & Media & Chairperson of work council & Online media & $>250$ \\
\hline 17 & $\begin{array}{l}\text { Information and } \\
\text { communication technology }\end{array}$ & $\begin{array}{l}\text { Chairperson of work council and member of the } \\
\text { supervisory board }\end{array}$ & Technology and Innovation Committee & $>10,000$ \\
\hline 18 & Logistics & Deputy chairperson of corporate work council & Member of the IT Committee & $>100,000$ \\
\hline 19 & Banking & Member of work council & $\begin{array}{l}\text { Member of committees for the adoption of } \\
\text { resolutions, e.g. on topics related to digitization }\end{array}$ & $>1,000$ \\
\hline 20 & Banking & Quality manager and member of work council & Payment service provider & $>10,000$ \\
\hline 21 & Logistics, consignment & IT-expert & System administrator & $>50,000$ \\
\hline 22 & $\begin{array}{l}\text { Information and } \\
\text { communication technology }\end{array}$ & Director Human Resources & Operation of IT systems for customers & $>10,000$ \\
\hline 23 & Academia & Director of university campus & Research and teaching on industry 4.0 & $<250$ \\
\hline
\end{tabular}




\section{B. A. Latos et al. / Advances in Science, Technology and Engineering Systems Journal Vol. 3, No. 5, 166-185 (2018)}

The questionnaire guide was divided into four parts. In a first step, demographic information on the interviewees was documented. The second questions asked for aspects that change companies and labor through digitalization; e.g. question were: what are the main digitalization-related changes in your company within the last 10 years? Which important changes do you anticipate for the next 10 years? The third question part focused on whether and how digitalized labor systems result in higher complexity levels. Therefore, the experts should name complexity drivers which are caused by digitalization for the six organizational dimensions respectively. In the final part of the interview, the experts were asked to identify measures to manage complexity in digitalized labor environments. Figure 5 summarizes the content of the interviews. The detailed questionnaire guide is included in Appendix 1.

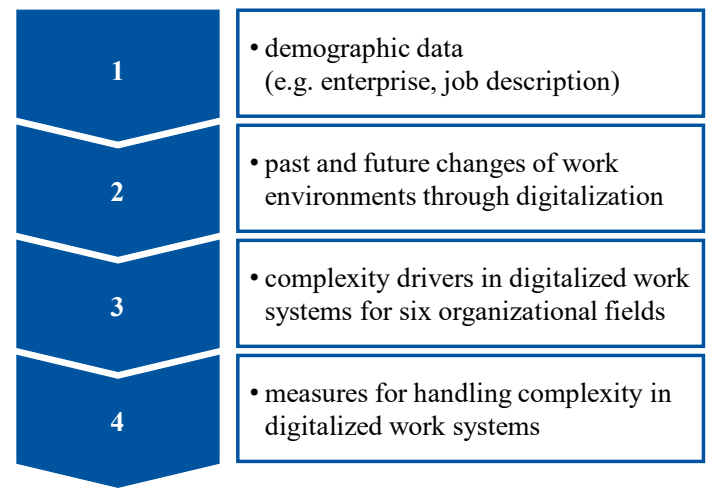

Figure 5: Structure of the interview template

The analysis process initially incorporated a verification of the transcription documents. This was conducted with the available sound recordings of the interviews. Then, the single interviews were qualitatively analyzed via employing the methodology of qualitative content analysis [48][49][50].

A qualitative content analysis is a systematic and intersubjective verifiable text analysis procedure that meets the needs of interpretation and semantic meanings of a linguistical research basis [51]. In contrast to quantitative content analyses, the main purpose is not to discover quantitative connections, but rather to reduce a large amount of analysis material and to extract the main contents. This makes the method especially useful for explorative studies. Mayring [48] describes a systematic and rulebased analysis approach. The structured and transparent procedure enhances the reliability and validity of the analysis. In this case, the general procedure was adapted to the specific research aim.

In a first step, a qualitative-interpretative analysis of every interview was conducted. As code unit, a single word was chosen and a whole sentence structure was defined as context unit. Furthermore, the analysis unit was structured according to the interview template. Within the analysis procedure, the statements of the experts were generalized, paraphrased and reduced to elementary categories. The categories were derived by using a hybrid approach of deductive and inductive category formation. The inductive approach was chosen, since the research did not aim at confirming existing theories. The aim was rather to extract general statements from the interview material. However, deductive analysis elements were included, as statements were assigned to expressions that are well established in literature. For example, the expression "polytely" (cf. section 2) was chosen as category name for expressions that contained phrases such as "conflicting goals" or "different goals that cannot all be reached at the same time". This simplified a purposeful assignment of the interview phrases.

In a second step, the single analysis results were combined and aggregated with a quantitative analysis of mentioned categories. This made it possible to describe how often a certain category was mentioned by the interviewed persons. By doing so, complexity drivers were extracted via counting the number of mentions for single driver categories within all 6 organizational dimensions. Figure 6 summarizes the whole analysis procedure.

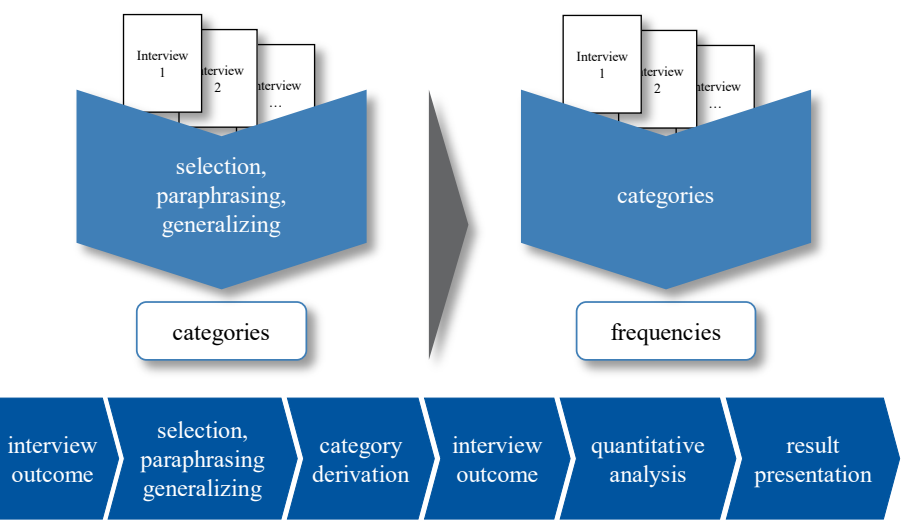

Figure 6: Procedure of qualitative content analysis according to Petz et al. [52], Duckwitz et al. [53]

According to Mayring [48], a qualitative analysis should meet two major quality criteria. On the one hand, intra-code-reliability requires that a repeated analysis procedure of the same coder after a certain time should lead to similar results. On the other hand, inter-code-reliability means that different persons will achieve similar analysis results. As the method is an interpretative approach, there will always be slight differences in the results, e.g. concerning the wording of categories between different coders (see e.g. [48]). With this analysis procedure, one repeated analysis by the initial coder as well as one further analysis with an additional coder was conducted. In both cases, similar results were extracted from the interviews which can be seen as indication for meeting the reliability criteria.

\section{Results}

In this section, the results of the aforementioned qualitative content analysis procedure are presented. In the first subsection, past and future changes of work environments through digitalization that were extracted from the interviews are outlined. Subsequently, the derived complexity drivers are presented for every organizational dimension, respectively. In the third subsection, the results for measures to handle complexity in digitalized labor systems are displayed.

\subsection{Past and future changes of work environments through digitalization}

Concerning the last 10 years, the experts pointed out diverse changes within their companies that have been caused through digitalization. The main changes are due to the new opportunities of manufacturing customized products. In addition, a development 


\section{B. A. Latos et al. / Advances in Science, Technology and Engineering Systems Journal Vol. 3, No. 5, 166-185 (2018)}

towards hybrid products in production industry was named. This means that the product is enhanced with further service options for the customer.

Also, the experts stated that former manually documented procedures have been changed into digital processes. These workflows incorporate several companies so that the dynamics and speed of these procedures have considerably increased as well as the duration for reactions has become shorter. Enterprise software, information and communication tools and cheaper sensor technologies offer the opportunity for companies to track and process big amounts of data. However, the operators within the companies very often have a problem to interpret and mentally capture these masses of information. As a solution for this problem, the use of big data algorithms was proposed.

Employing information and communication technology remarkably altered every day work procedures, since the amounts of interpersonal face-to-face communication are reduced. Nowadays, (digital) work forms of collaboration can be observed increasingly. Portable devices such as mobile phones, tablet computers and netbooks make it possible to perform the job in flexible work forms in terms of location and time. This gives employees more flexibility and enhances family friendliness of enterprises, whereas the persons at the same time have the drawback of possibly being always available. The interviewees concluded that these changes rather relate to administrative departments and service sectors than to manufacturing. Within the service sector, value creation networks have a higher level of digitalization than in manufacturing.

With respect to the next 10 years, the interviewees predicted increasing and quicker rates of process changes. Consequently, data will not be documented manually any more. Planning procedures will be complemented with digital support tools as well as data in real-time will be provided. Concerning manufacturing steps, the interviewees pointed out that planning and controlling would change from an internal enterprise-focused view towards an approach that considers whole value-chains. Furthermore, business models will more and more tend to include services. Therefore, products will include more software and will be a medium to offer services to the users of the products. For instance, a car manufacturer will no longer be only selling cars but rather mobility, since the car offers supplemental services to the customer.

Although experts that represented employees feared big job losses because of digitalization, the majority of the interviewees agreed that operators would not be replaced in labor systems. However, different tasks and qualification requirements will develop so that there will be new job types.

\subsection{Complexity drivers in digitalized work systems}

Although the interviewees did not all have the same occupational backgrounds, the overall analysis indicates that similar points can be generalized from the single interviews. In total, the analysis results show that a considerable development towards very adaptive procedural and structural organizations is required for meeting the environmental demands and to evolve to customer-focused production procedures. This development is made possible through digitalization of manufacturing and service procedures. Nevertheless, this causes a higher complexity level.

Regarding the organizational dimension of process organization, the experts answered that complexity increases due to more customer involvement into faster work procedures. This calls for reactive and adaptive planning processes. Since digitalization can be used to initiate reactions in a company in realtime via using novel technology, this remarkably raises the dynamics of the whole organization. The change towards worldwide active value creation networks with several levels also increases the overall complexity. Since labor systems are more digitalized, the amount of human machine interfaces and diverse system solution rises. In this context, parallel IT-systems may increase the complexity level because of several maintenance and data processing steps. This may in turn cause data redundancies and problems of lacking data hygiene. Furthermore, media changes during work processes were mentioned as roots of complexity, which is digitally solvable via solutions for integrated systems. Figure 7 summarizes the drivers in the dimension of process organization and their number of mentions. Since every expert could mention several or no complexity drivers for every organizational dimension, the number of mentions does not necessarily have to sum up to the number of experts.

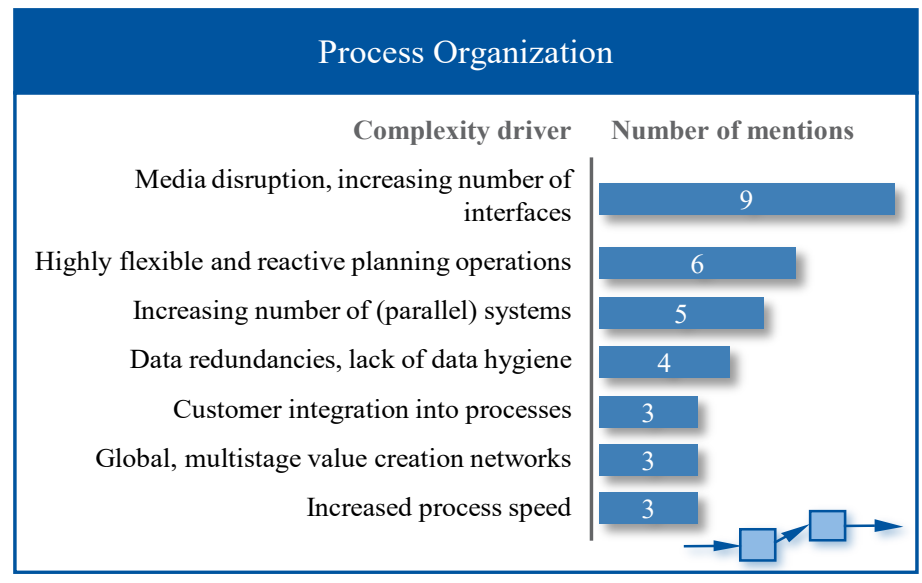

Figure 7: Complexity drivers in digitalized work environments concerning process organization, including their number of mentions

To develop such adaptive enterprise organizations, a shift of traditional hierarchic organizations towards the direction of flatter hierarchies is necessary. Almost all interviewees agreed on the point that agile work methods and project work would be most frequently found in the course of digitalization. In this context, complexity with respect to the organization increases, when a development towards trans-disciplinary work in (worldwide) structures is needed. This causes more coordination procedures. To work in smaller and agile cooperative structures also causes that employees need to be given more autonomy. The targeted final state may make it easier to fulfill market demands. However, the procedure of changing the culture in an organization was seen as raising the complexity level in a first step. If work persons are not empowered and qualified in diverse dimensions, occurrences with conflicting goals (polytely) can imply complexity for single operators. Complexity drivers and their number of mentions regarding the dimension of structural organization are illustrated in Figure 8. 


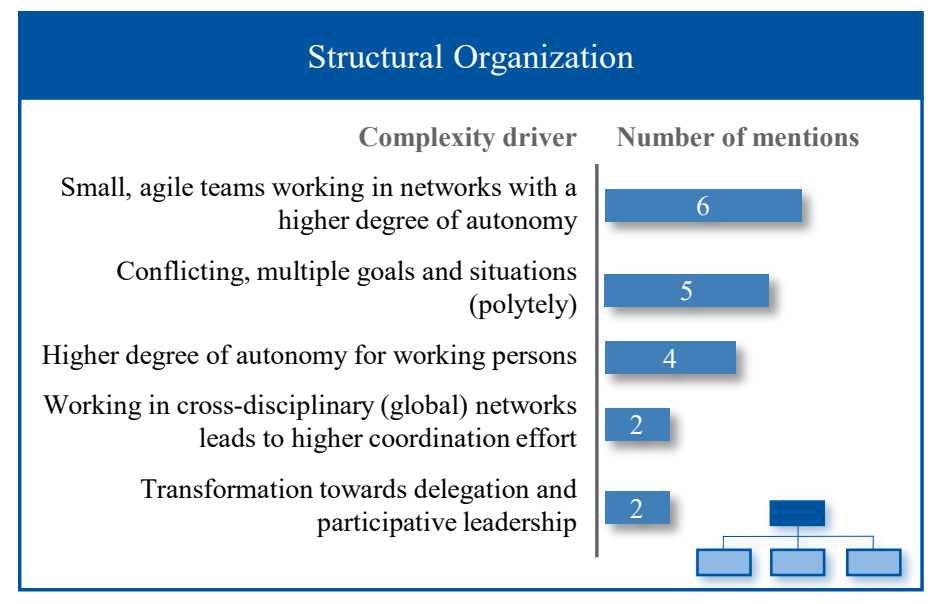

Figure 8: Complexity drivers in digitalized work environments concerning structural organization, including their number of mentions

For the organizational dimension of technology, the experts named rising requirements for IT security as most important aspect in digitalized labor systems. Systems that are not compatible, missing technological standards and lacking common sets of protocols increase complexity during digitalization. These aspects gain importance, since harmonization problems happen because of systems that have evolved over a long time span. Furthermore, much higher information amounts need to be captured in real-time with software to analyze the data. Faster innovation cycles with respect to software and hardware cause more dynamics of introducing novel systems. Figure 9 summarizes the drivers concerning technological aspects and their number of mentions.

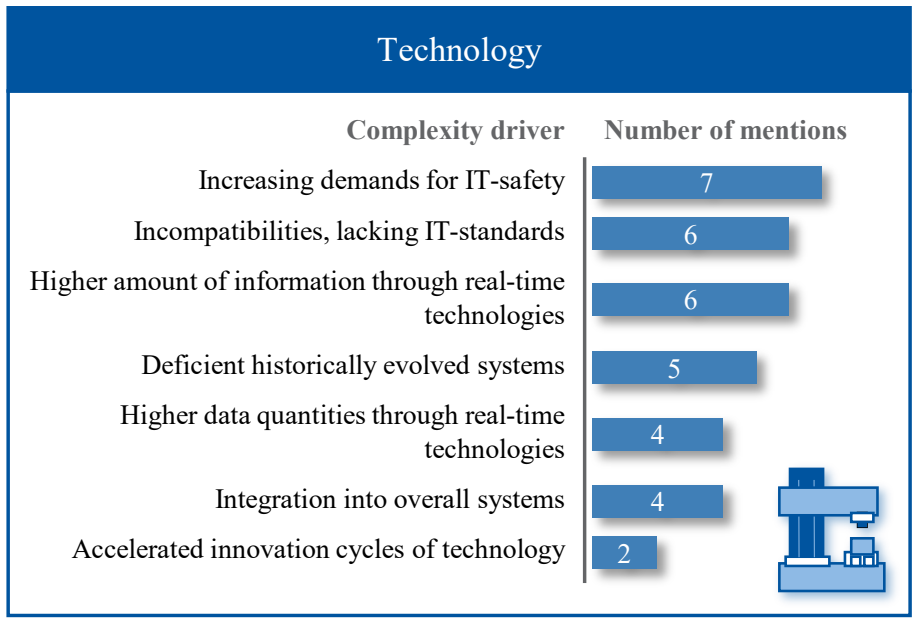

Figure 9: Complexity drivers in digitalized work environments concerning the technology, including their number of mentions

Digitalization will also have an effect on the conditions of work and will make new methods of digital communication possible. However, mentioned by the interviewees, only communicating digitally could not totally replace interpersonal communication and cause communicational complexity, because the semantic meaning of expressed phrases is mainly strengthened with face expressions or gestures. For this reason, hybrid communication ways should be considered. The majority of the interviewees stated that the digital transformation in general changed jobs into the direction of tasks that have to manage more complexity. Although monotonous tasks are likely to be replaced by automation, jobs that demand analytical information processing, creative thinking and the capability of solving problems combined with specialist skills are more and more required. This causes that employees need transdisciplinary abilities (for instance, qualifications such as selforganization or multidimensional work with respect to diverse disciplines). Task complexity occurs as well, if novel digital systems are used and if more digitalized information has to be captured mentally in a shorter time. Lots of interviewees stressed on the point that this facet already produced trouble for employees in many cases. If the rising amount of operator machine interfaces was not created in a way that they can be used easily, a higher level of complexity would be a consequence for the employees. Nevertheless, single interviewees mentioned that the use of digitalization could at the same time be employed to make work easier. For example, work instructions can be provided during the task fulfillment. A further point is that the digital transformation could cause more task quantities. In this context, scan devices facilitate to introduce inventory documentation jobs into work procedures. All in all, a major complexity cause in digitalized labor systems was identified in the point that digitalization frequently is not very well established in management hierarchies. Particularly for worldwide operating organizations, the significance of different laws and agreements for data protection in diverse nations has extensive consequences. Figure 10 illustrates complexity drivers in the dimension of working conditions.

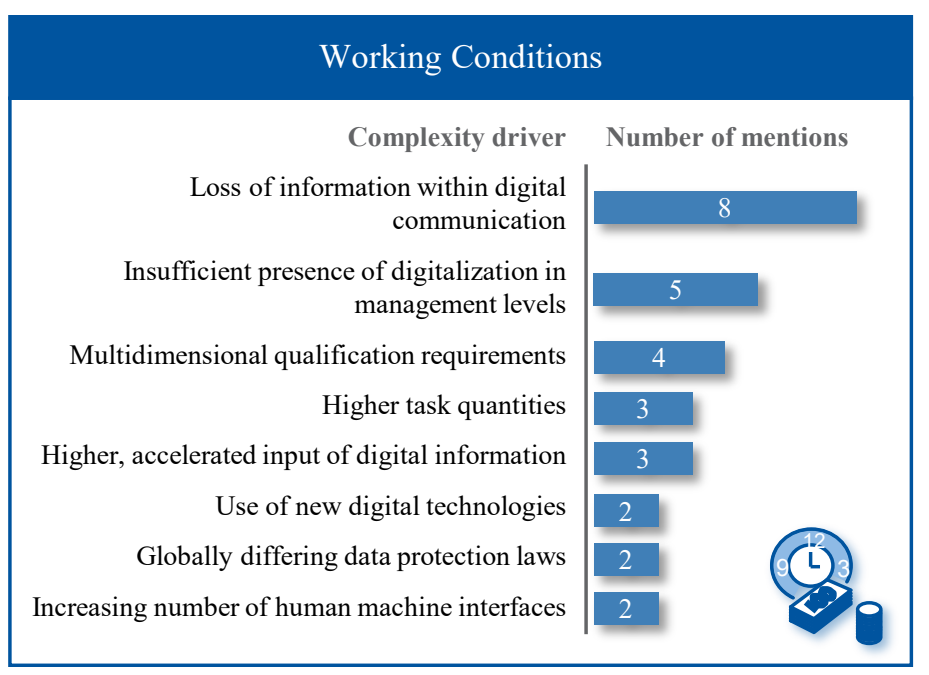

Figure 10: Complexity drivers in digitalized work environments concerning working conditions, including their number of mentions

With respect to the organizational dimension of products, the interviewees named individualized products and more product variants as main complexity drivers. In general, digitalization causes product and service portfolio complexity because sensor devices, software and connecting elements are important parts of a product. This implies that designers of goods and machines will have to take into account that the final product is going to be used in a web-based context. These changes remarkably enhance feasible functions of the product but also cause more software dependency. The radical development from typical products towards hybrid production necessitates that the whole life-cycle of a produced good will need be regarded during the development of the product. Since producers and customers will not only interact once when selling a smart product, they will likely be in close contact during the whole life-cycle when processing data packages 


\section{B. A. Latos et al. / Advances in Science, Technology and Engineering Systems Journal Vol. 3, No. 5, 166-185 (2018)}

are transferred. This provides numerous novel options and makes a product more complex. For instance, individualized services or upgrades may be suggested as well as novel business models that are based on data analyses will come into focus.

In addition, very iterative and accelerated product development procedures in which clients work with the contractor together were mentioned as complexity drivers. This process of co-development between companies is essential, since a considerable gain in ITskills and system thinking develops on the client side. In particular within the service sector, digital opportunities are employed to integrate the customer (business-to-customer relation) into the development of new services and into the service delivery. In the context of self-service, digital procedures make it possible to outsource tasks to the customers and to let them directly take part in the service fulfillment. In analogy to the organizational dimension of technology, the interviewees mentioned that digitalization fastens the release cycles for new innovations or products so that the complexity level of the products increases. Figure 11 summarizes the complexity drivers concerning the product.

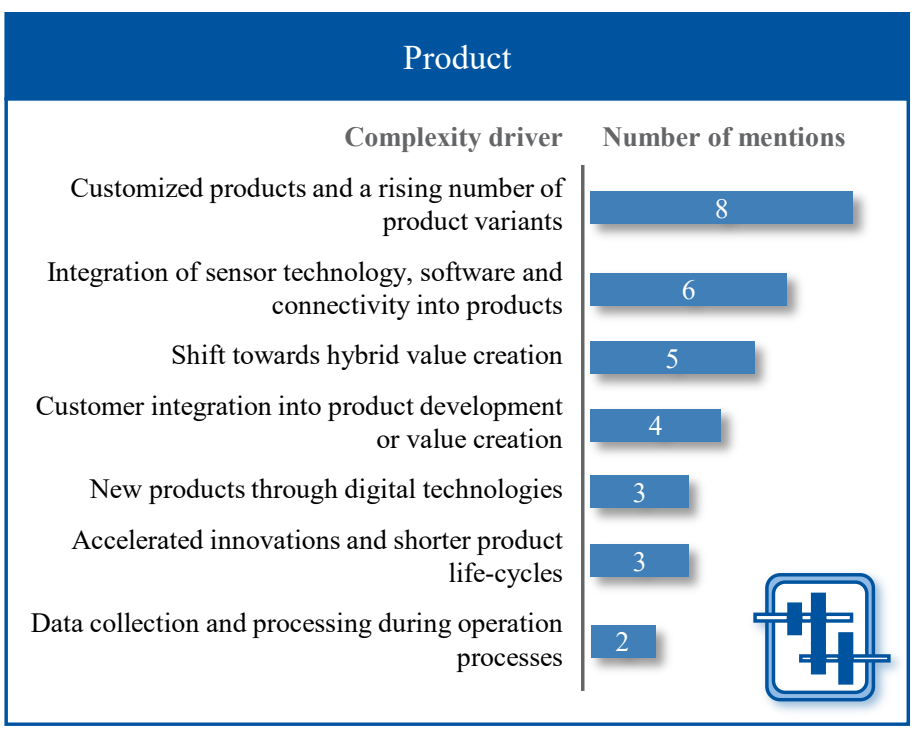

Figure 11: Complexity drivers in digitalized work environments concerning the product, including their number of mentions

Concerning the organizational dimension of personnel, the interviewees said that qualification requirements for more digital understanding and skills are the most important aspect for handling the complexity in digitalized labor systems. However, the operators very frequently do not have the needed competencies. Moreover, a major gap of IT understanding between employees can be detected. Also, digitalization offers the possibility to work in mobile and flexible work conditions. This allows for balancing the private life and the job. Nevertheless, this also can cause very complex situations for the staff, because contrary requirements could evolve from the trend that makes the separation between the job and free time more difficult. The employment of mobile gadgets also implies that an employee is always available. This can be the cause of a dependency on technology to some extent. Additionally, severe problems were mentioned that concern the aspects measuring and controlling the performance of the personnel in labor environments. If new places of work are conceptualized for digital work systems, the complexity of planning increases due to missing approaches for strain measurement. Furthermore, there is a lack of rules and relief concepts for digital work. Ultimately, many experts stated that digitalization offers novel job forms, such as crowdworking. This may have major implications for single persons or whole organizations. In addition, this can also imply complex problems for societies. These could be related to topics of social exclusion or regulatory problems for whole systems due to lacking contributions to social insurances. Figure 12 summarizes the complexity drivers concerning the personnel.

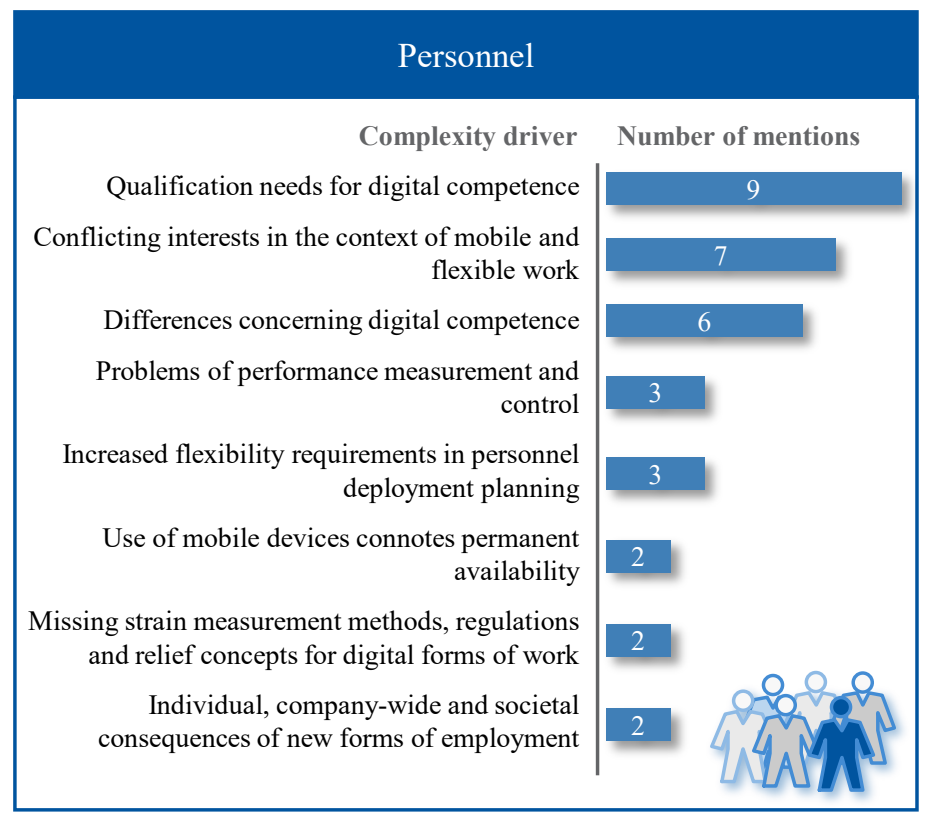

Figure 12: Complexity drivers in digitalized work environments concerning the personnel, including their number of mentions

\subsection{Measures to handle complexity in digitalized work systems}

The interviews were also used to explore measures to manage complexity in digitalized work systems. Adequate training of employees was most frequently mentioned by the experts. On the one hand, this implies qualifications for imparting methodical and expert knowledge on new technologies, processes and work equipment. On the other hand, training includes enhancement of social and communicative competences, which are targeted e.g. at avoiding or solving communication problems and conflicts in cooperative decision-making processes. Training was also considered as necessary to support employees coping with mental and physical strain as a consequence of changing or increasing job requirements.

The second most frequently mentioned measure was participation. Employees that are affected by digitalizationinduced change should not only receive adequate training, but also should be involved in change-related development and decisionmaking processes at an early stage. Participation in pilot projects for implementation of new technologies and communication tools was mentioned as an example in order to enhance acceptance for digitalization-related innovations and to ensure economic efficiency. Additionally, participation-oriented pilot projects were recommended to design user-centered support systems and identify policies or required formalities on the following aspects: workload, working time, occupational safety and data protection. 
In this context, work in agile teams was, for example, seen as form of work that especially requires policies concerning these aspects.

Development and use of algorithms for automatic data analyses were proposed as further measures to handle complexity. Thus, increasing data volume and diversity in the course of digitalization could be limited to the information and key figures required for the specific application. These and similar measures aim to relieve employees from analyzing and processing large amounts of data. The resources saved can be used for the accurate interpretations of data, which still need to be carried out by employees.

To harmonize different systems and their interfaces, the development and introduction of reference architectures for IT systems were mentioned. A modular structure of IT systems enables further development and easier linking of new technologies to the overall IT system. The definition of IT standards and the standardization of the IT structure help to avoid interface problems and to ensure the interoperability of the systems used. According to the experts, simple operation of products and systems is an equally important measure, e.g. through intuitive user guidance and ergonomic interface design. While this results in potentially more demanding programming, there are various benefits: avoidance of handling problems and errors, reduction of operating effort, and reduction of qualification effort during introduction and application of newly introduced technologies and systems.

The experts also mentioned the development of more transparent business processes to clarify responsibilities and avoid misunderstandings in work instructions due to inaccurate communication or misleading information. This also aims at a solid understanding of processes of all employees and managers as well as better overall communication.

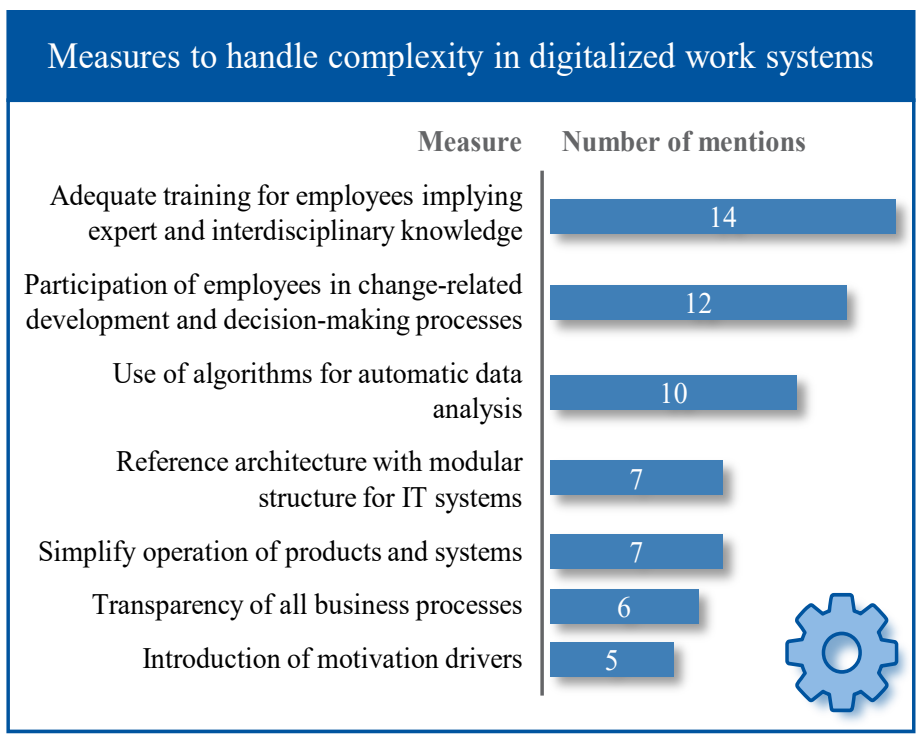

Figure 13: Measures to handle complexity in digitalized work environments including their number of mentions

Finally, the introduction of motivation drivers includes measures that can or should contribute indirectly to mastering the resulting complexity by promoting the willingness of employees to change. Motivation drivers could be e.g. suitable break concepts, more varied activities or "gamification" approaches combined with monetary incentives. Figure 13 illustrates the categorized measures to manage complexity in digitalized work systems as a result of the interview analysis.

\section{Implications for cooperative forms of work}

The results of the expert interviews have far-reaching implications for cooperative forms of work. In this context, the term cooperative form of work is employed to express that people work in a team or group structure and thus exhibit interaction amongst each other whilst performing their job. This includes a project team as well as a work group in a production environment.

In the literature, there is already extensive research on team or group work that describes the interrelations of relevant variables, e.g. in team models (e.g. [54][55][56][57]; overviews can be found in [19][58][59]). These models often focus on teamwork in the context of innovation and do not consider complexity parameters. Only a few conceptual and non-empirically validated models (e.g. [60]) contain "task complexity" in the context of cooperative forms of work as a single complexity-related variable. The expert interviews revealed that the ratio of cooperative forms of work is expected to grow in the field of production. A literature review of existing models for cooperative forms of work shows that currently there is no interrelated and empirically assessed model for group work in production and thus no consideration of complexity in a superordinate model (see e.g. [59]). Therefore, further research is necessary in this field. Such a model could be developed conceptually as an input-process-output model (see e.g. [19]). This approach enables to investigate the effects of digitalization and complexity as input factors on process and output dimensions. The interview results offer diverse aspects that directly refer to cooperative work. These aspects could be integrated into the development of such a new model. By doing so, the explorative results of the interviews, which originally did not aim at confirming existing theories, could be used to develop hypotheses, new theories and an overall framework for analyzing cooperative forms of work.

When regarding the dimension of structural organization in the interviews, a transformation towards cooperative forms of work was the most frequently mentioned complexity driver for digitalized work environments. Small and agile teams working in network structures with a high degree of autonomy were considered by the experts as a predominant form of work in the late stage of digital transformation processes. This can be seen as a continuation of the trend observed by the experts, which already describes a change towards cooperative forms of work over the past 10 years. These results strengthen that team and group research will increasingly come into focus - particularly in the course of digitalization. This conclusion is also reached by Trompisch [61].

Hence, there is a need for further research on group processes on the one hand and to explicitly focus on the effects of digitalization on cooperative forms of work on the other hand. In addition, the results of the expert interviews showed that digitalization does effectively imply complexity-driving aspects that have an impact on working persons. For this reason, it is also necessary to apply complexity considerations to cooperative forms of work and to investigate complexity in greater depth in this context. 


\section{B. A. Latos et al. / Advances in Science, Technology and Engineering Systems Journal Vol. 3, No. 5, 166-185 (2018)}

Assuming that humans do not have a stable input-output relationship [62] supports the consideration of human behavior and perception in complexity studies, e.g. with regard to emergent events [63]. For example, a user of a new digital system could use the system for a completely different purpose compared to the original goal of the system. If this individual view was transferred to a work group consisting of several individuals, it seems trivial that the interaction of several people can especially be classified as complex. From a system theory point of view, a work group, e.g. a team of workers in production, can be seen as a complex structure or subsystem within the complex company system. In this context, the characteristics of complexity from system theory that were derived in the first section of this article can be considered and transferred to the system "work group".

On the whole, it is essential to consider factors such as digitalization and complexity in a differentiated manner. Complexity may contain positive and negative aspects concerning both organizational levels (e.g. [17] [64]) and individual levels. On the company level for instance, a larger variety within a product portfolio - and thus greater complexity - can be used to respond to changing market requirements and thereby to achieve competitive advantages. However, an excessive broad product range also bears the risk of strong cross-subsidization effects and thus economic losses (see e.g. [65] [66]). As the focus of this article lies on work design, the individual level concerning work persons will be discussed in more detail.

For an individual person and in analogy to the Yerkes-Dodson law, Dalhöfer and Prieß [15] conceptually describe the influence of task complexity on the individual performance and motivation in the context of indirect business processes with an inverted ushape parabola. The decline in performance for tasks that are less complex than the optimum task complexity is explained with demotivation due to highly monotonous activities. The area near the parabola's apex describes an optimum of task complexity in which the worker is challenged in a positive sense by the work task and thereby is highly motivated. The decline in performance to the right of the complexity optimum is caused by the employee being overloaded by the work task. Regarding the individual skills of the working person, the task becomes too complex so that work performance and motivation decrease. Since complexity is not clearly measurable due to the subjectivity of its perception, and a slight change in complexity does not necessarily lead to immense changes in performance, an interval for acceptable task complexity should be defined. Dalhöfer and Prieß [15] use the term "EuStress" (good stress) to define the term "Eu-complexity" (good complexity). This term describes the range around the complexity optimum in which a high performance is achieved. In analogy, they describe the area of overload as "Dys-complexity". Figure 14 illustrates these conceptual considerations.

It is important to note that the curve trace of the parabola and therefore also the interval boundaries vary in analogy to the stressstrain concept [37][38] between different persons.

In general, the individual parabolic curve can be explained either by constitutional characteristics, disposition characteristics, qualification and competence characteristics or by adaptation characteristics of a worker [19]. Constitutional characteristics (e.g. gender, body type, nationality etc.) are invariable in a person's life- cycle so that it is difficult to change a person's ability to cope with the required task complexity. This also applies to disposition characteristics (e.g. personality, age, intelligence, body weight etc.) which can be changed over time - even though not directly by the employee. However, qualification and competence characteristics (e.g. experience, knowledge, skills, education, competence etc.) can be varied through long, medium and shortterm work structuring processes. For instance, dedicated training can help to ensure that a work task is no longer perceived as too complex, i.e. more complex than the complexity optimum of the parabolic curve, by the individual worker. In this context, Dalhöfer and Prie $\beta[15]$ regard the line manager as key figure in complexity management, as the complexity optimum could individually be designed for every employee. Finally, short-term work structuring measures may lead to a variation of adaptation characteristics (reaction to energetic-effector, informational-mental or emotional stress; e.g. strain, fatigue, satisfaction etc.) and to a reduction of subjectively perceived task complexity, e.g. through supporting information systems.

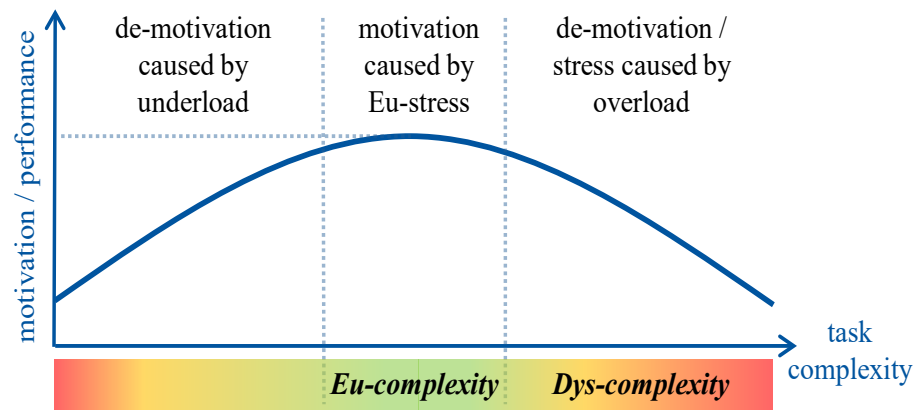

Figure 14: Performance, motivation and task complexity according to Dalhöfer and Prieß [15]

This article makes the first attempt to extend these conceptual considerations towards cooperative forms of work and hence further developing the concept of Dalhöfer and Prieß [15]. For the example of a work group, it is assumed that the original concept for the individual worker still is valid. Thus, each work group has individual complexity parabolas for each person in this group. The individual complexity parabolas are now transferred into a threedimensional diagram, which contains the individual persons of the work group as a third axis. This creates a three-dimensional graph that can be covered with an envelope curve. In this article, the concept of a "task complexity mountain range" of a work group is introduced as a metaphor. This concept is illustrated in Figure 15.

It is evident that although the task complexity mountain range is composed of the individual graphs, the interval of a complexity optimum also exists for the work group as a whole. The interval appears through the envelope curve, which covers the individual graphs. However, this optimum cannot clearly be determined due to the different apex points of the individual parabolas and can only be described as an interval in which the abilities of the group members complement each other. Within this interval, the overall complexity of the group's work task needs to be distributed adequately according to the individual complexity parabolas of the particular group members. However, identifying the optimum is already a complex task, as the optimum may shift dynamically depending on the group structure and internal group processes. 


\section{B. A. Latos et al. / Advances in Science, Technology and Engineering Systems Journal Vol. 3, No. 5, 166-185 (2018)}

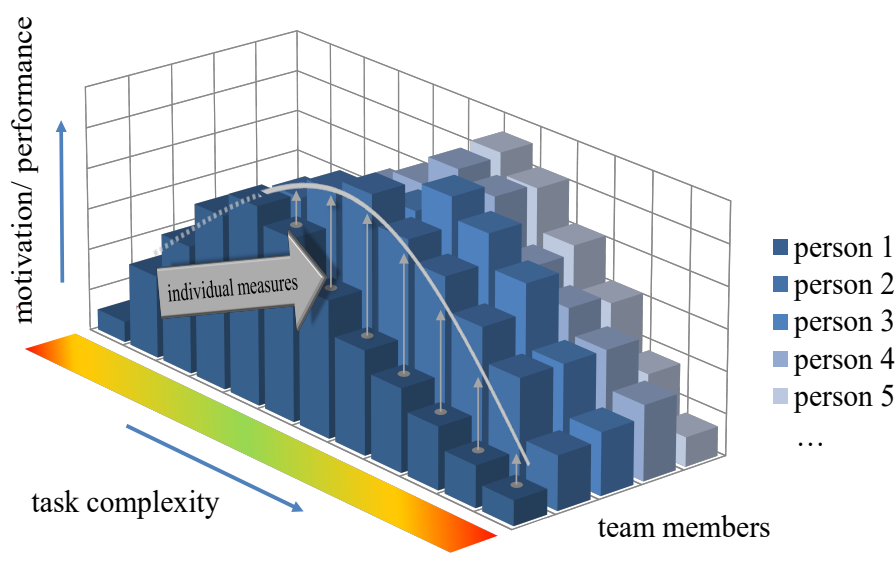

Figure 15: Development of the individual task complexity concept of Dalhöfer and Prieß [15] towards a "task complexity mountain range" for cooperative forms of work; including individual coaching measures to adjust the complexity curve of person 1

In the context of cooperative forms of work, the concept of leadership in complexity management of Dalhöfer and Prieß [15] is even more important: within the group, the line manager has to respond to individual working persons and individually adjust the complexity optimum. In Figure 15, the arrow labelled "individual measures" indicates that through dedicated training the complexity optimum of a particular person - and in a reverse conclusion of the entire work group - can be shifted towards more complex work tasks. For instance, this is achievable by systematically enhancing the individual qualification and competence characteristics. In addition, the work group as a whole can be enabled by the line manager to handle more complex tasks independently and to react adaptively to unpredictable situations. Transformational leadership, for example, can achieve this by strengthening the intrinsic motivation of employees through transforming their values and ambitions as well as supporting the individual development [67]. ElMaraghy et al. [17] point out that collaboration is able to lead to adaptive and creative forms of work that can handle complexity very effectively.

However, the expert interviews have shown that the transformation towards delegating and cooperative management initially increases complexity - and that sufficient complexity handling can only be achieved in the target state of the transformation process. Also, participation was identified in the expert interviews as most frequently mentioned measure for managing complexity in digitalized work systems. This should consequently be a subject of research in the context of management of work groups. With regard to management processes, goal-setting theory [68] should also be examined in greater depth. For instance, the effect of conflicting goals on work processes of groups with a high degree of autonomy should be inquired. The expert interviews have indicated that a higher degree of autonomy and conflicting objectives increase complexity for working persons and that these aspects are intensified in the course of digitalization. Therefore, further research is needed to determine how a good target quality can be achieved for work groups. Overall, especially in the context of digitalization, an intensive investigation of cooperative leadership processes in group work is particularly relevant in order to develop strategies for complexity management for work groups.
According to Schuh and Riesener [65], corporate complexity management strategies for optimizing the product portfolio not only include measures to handle complexity, but also measures to avoid and reduce complexity. These could also be applied to complexity management of group tasks. Thus, there are two further strategies for designing the "optimal" task complexity for work groups: on the one hand, task complexity can be reduced via redesigning the work process (corrective approach), if the level of task complexity lies within the interval that decreases work performance and motivation due to overstraining conditions. On the other hand, task complexity is initially avoidable in terms of preventive work design.

The degree of optimal task complexity of a work group or team also always depends on the operational conditions. As an example, resources provided, support from other organizational units or digital support tools determine how well complex tasks can be solved by the work group. However, the use of digital support systems also requires a differentiated consideration: the expert interviews have shown that digital assistance systems are able to reduce complexity if they are designed in a user-centered manner. In addition to participatory development processes, which have the potential to increase acceptance of new systems, there are instructions for ergonomic designs of such systems in norms, e.g. in EN ISO 9241 [69]. Nevertheless, the interview results also showed that perceived complexity of a work task may increase due to user-unfriendly designs of digital work tools. In addition, the perceived complexity depends on the life-cycle phase of the support system. It is important to distinguish whether the system is currently being introduced in the company, adapted or already established. Even though a new digital support system may be intended to make complexity manageable in a work system, the introduction of a new system will initially generate a (subjective) increase in complexity. Initially, the system is unfamiliar and requires training. This phase is followed by an iterative phase in which the employees become familiar with the use of the system. At the same time, possible system errors are eliminated and the system is adjusted to the needs of the employees. In the third phase, the "steady state", the intended subjective complexity reduction of the work task is sustainably realized. The interviews indicated that a participatory development and testing procedure of such systems facilitates to reach this target state in a shorter period of time. To accompany this, appropriate training for the use of the systems should support the introduction process. Figure 16 illustrates the settling process of digital support systems with regard to perceived task complexity.

Overall, it is apparent that considerations relating to complexity and digitalization in the context of cooperative forms of work offer multifaceted research questions. In order to contribute to bridging the identified research gaps, a holistic empirical analysis of the interrelationships in a structural equation model is suggested (see e.g. [59]). Further research steps and a general discussion are considered in the following section.

\section{General discussion and future research steps}

Diverse disciplines conduct research on the construct of complexity with specific points of interest and with different methods. This article explored complexity drivers that arise through digitalization. The qualitative content analysis of the 


\section{B. A. Latos et al. / Advances in Science, Technology and Engineering Systems Journal Vol. 3, No. 5, 166-185 (2018)}

interviews identified various complexity drivers in digitalized labor systems in all six organizational dimensions. They may be employed to enhance current complexity driver systematizations that already exist in literature.

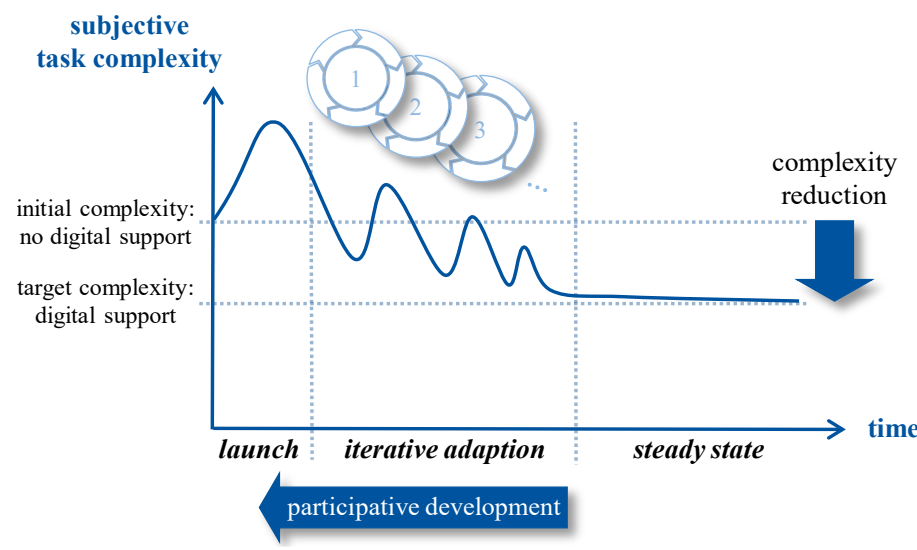

Figure 16: Settling process of digital support systems with respect to subjective task complexity

Since digitalization changes labor systems and whole industrial sectors, it is crucial to gain a deep understanding of which factors raise the level of complexity not only from a technical but at the same time from a work design perspective. The findings show that the supply of lots of information as well as diverse options of displaying them may imply complexity for employees in a negative connotation. This is why it is crucial to agree on guidelines for company-internal communication. A lower level of complexity is obtainable by reducing the number of communication systems. Moreover, information should be organized and supplied in a manner that makes is easy for operators to spot the information that is needed by them to perform their jobs.

However, it is frequently based on the viewpoint whether a certain topic should be seen as a driver of complexity. In this connection, the complexity drivers belong to various points of view which relate to whole systems as well as to subjectively perceived complex incidences from the perspective of an employee. Regarding the operator's perspective, a new digital support system could reduce complexity for an operator, if it was well designed. Yet, complexity rises on a system level, as the amount of system elements and system maintenance procedures increases.

Furthermore, it should be mentioned that the organizational dimensions cannot be examined separately, since they are interdependent in diverse ways. This is why it is especially complicated to assign drivers to particular dimensions. The validity of the results of the analysis procedure can be increased by enlarging the sample size of interviewed experts. This could enable cross-references with the results of the interviews as well as complexity drivers could be identified that are specific for certain industrial sectors. All in all, the conducted method of semistructured interviews with experts enabled to qualitatively analyze the answers of the interviewees. Therefore, this method was adequate for the first research step of exploration. If conducted with sufficient many persons for the coding procedure, the method may offer reliable results. However, the inter-code-reliability of the results can be enhanced and quantitatively judged by repeating the analysis procedure with more than two coders. Further research steps will use the findings to develop theories and to conduct ongoing quantitative empirical studies.

This article discussed the findings in the context of cooperative forms of work and offers initial concepts that will be examined with empirical research methods in future. The studies will have to show whether the concept of the task complexity mountain range should be retained or adapted. Furthermore, the effects of digitalization on output and process measures of cooperative forms will be assessed.

Eventually, complexity should not be seen unequivocally as a thing that should be avoided at all costs. Actually, complexity is also the basis for market leadership, if enterprises have an expertise in reproducing the demanded market complexity. However, the important question is how much capacity is required to fulfill these requirements so that too complex organizations can be prevented. This especially leads to the overall challenge of how work systems should be designed to provide rather challenging than overstraining work conditions for employees.

\section{Conclusion}

This article examined which complexity drivers in labor systems are caused by digitalization. Initially, diverse complexity definitions from relevant research disciplines were presented. General properties of complexity in theory were identified. Moreover, the used method of semi-structured interviews with experts for exploring the complexity drivers was outlined. The group of interviewees was made up of 23 experts with positions in German economy and science. The findings show that the digital transformation could remarkably alter work processes and whole industrial sectors. In this connection, diverse complexity drivers in digitalized labor environments were explored and clustered into six organizational dimensions. The findings can be employed to point out far-reaching consequences of digitalization, because the six organizational dimensions and the topics of complexity and digitalization are mutually interrelated. Further, measures for handling complexity in digitalized work systems that were extracted from the interviews. The findings were discussed in the context of cooperative forms of work as well as existing concepts for explaining complexity impacts were transferred to this topic. In this context, the concept of the task complexity mountain range for cooperative forms of work was developed. Future research steps will attempt to empirically assess the complexity in digitalized labor systems. In this context, it will be analyzed which effects complexity and digitalization have on cooperative forms of work in production systems. The results may be used for developing additional measures to handle complexity in digitalized work systems to those that were presented in this article.

\section{Conflict of Interest}

The authors declare no conflict of interest.

\section{Acknowledgment}

The research and development project "TransWork" is funded by the German Federal Ministry of Education and Research (BMBF) 


\section{B. A. Latos et al. / Advances in Science, Technology and Engineering Systems Journal Vol. 3, No. 5, 166-185 (2018)}

within the program "Innovationen für die Produktion, Dienstleistung und Arbeit von morgen" according to Grant No. 02L15A162 supervised by the Project Management Agency of Karlsruher Institute of Technology (PTKA). The authors are responsible for the content of this publication. The authors would like to express their gratitude for this support.

\section{Appendix}

\section{Appendix 1: Questionnaire guide for the semi-structured interviews}

1. Name, company, company size, function and tasks in company 2.1 How has digitalization changed your company and business in the last 10 years?

2.2 How will digitalization change your company and business in the next 10 years?

3. How does digitalization influence the level of complexity in the 6 dimensions of work organization? Which aspects of digitalization cause a higher level of complexity?

a) Process organization (e.g. production planning, material flow, information flow, innovative assembly concepts)

b) Organizational structure (e.g. hierarchy levels, delegation of responsibility), decision-making powers)

c) Technology (e.g. production technology, information technology)

d) Working conditions / incentive systems (e.g. employment contracts, work safety, working hours, remuneration)

e) Product (e.g. product design, product structure, new business models)

f) Personnel (e.g. cooperation, communication, leadership, personnel planning, qualification)

4. What measures can be developed to manage the complexity caused by digitalization?

\section{References}

[1] B. A. Latos, M. Harlacher, P. M. Przybysz, S. Mütze-Niewöhner, "Transformation of Working Environments Through Digitalization: Exploration and Systematization of Complexity Drivers" in IEEE International Conference on Industrial Engineering and Engineering Management, Singapore, Singapore, 2017. http://dx.doi.org/10.1109/IEEM.2017.8290059

[2] G. Schuh, M. Riesener, J. Kantelberg, N. Steireif, “Transmission of softwarerelated agile mechanisms of action towards product development processes for technical products" in IEEE International Conference on Industrial Engineering and Engineering Management, Singapore, Singapore, 2017. https://doi.org/10.1109/IEEM.2017.8290192

[3] C. Châlons, "Die Rolle der IT als Enabler für Digitalisierung", In: F. Abolhassan (Ed.), Was treibt die Digitalisierung? Warum an der Cloud kein Weg vorbeiführt, Wiesbaden, Germany: Springer, 27-37, 2016. http://dx.doi.org/10.1007/978-3-658-10640-9

[4] C. Aichele, M.. Schöneberger, Die Digitalisierung der Energiewirtschaft: Potenziale und Herausforderungen der IKT-Branche für Utility 4.0, In: O. D. Doleski (Ed.), Herausforderung Utility 4.0. Wie sich die Energiewirtschaft im Zeitalter der Digitalisierung verändert, Wiesbaden, Germany: Springer, 501530, 2017. https://doi.org/10.1007/978-3-658-15737-1

[5] W. Widuckel, K. de Molina, M. J. Ringlstetter, D. Frey, Arbeitskultur 2020. Herausforderungen und Best Practices der Arbeitswelt der Zukunft, Wiesbaden, Germany: Springer, 2015. https://doi.org/10.1007/978-3-658-06092-3

[6] W. M. Walter, "Der Einfluss der Digitalisierung auf die Organisation eines Unternehmens", In: O. D. Doleski (Ed.), Herausforderung Utility 4.0. Wie sich die Energiewirtschaft im Zeitalter der Digitalisierung verändert, Wiesbaden, Germany: Springer, 227-248, 2017. https://oi.org/10.1007/978-3-658-15737-1
[7] W. Bauer, S. Schlund, "Wandel der Arbeit in indirekten Bereichen - Planung und Engineering", In: H. Hirsch-Kreinsen, P. Ittermann, J. Niehaus (Ed.), Digitalisierung industrieller Arbeit. Die Vision Industrie 4.0 und ihre sozialen Herausforderungen, 1st ed., Berlin, Germany: Nomos, 53-70, 2015. https://doi.org/10.5771/9783845263205-1

[8] Institut DGB-Index Gute Arbeit, DGB-Index Gute Arbeit. Der Report 2016. Wie die Beschäftigten die Arbeitsbedingungen in Deutschland beurteilen, Berlin, Germany: PrintNetwork pn / ASTOV Vertriebsgesellschaft mbH, 2016.

[9] O. Stettes, Arbeitswelt der Zukunft. Wie die Digitalisierung den Arbeitsmarkt verändert, Cologne, Germany: IW Medien, 2016.

[10] H. Hirsch-Kreinsen, "Digitization of industrial work. Development paths and prospects" Journal for Labour Market Research, 49(1), 1-14, 2016. https://doi.org/10.1007/s12651-016-0200-6

[11] L. Bertschek, B. Dworschak, P. Meil, T. Niebel, J. Ohnemus, T. Vetter, H. Zaiser, Arbeitsmarkt 2030 - Digitalisierung der Arbeitswelt. Fachexpertisen zur Prognose 2016, Munich, Germany: Economix Research \& Consulting, 2016. https://doi.org/10.3278/6004559w

[12] S. Schlund, B. Pokorni, Industrie 4.0 - Wo steht die Revolution der Arbeitsgestaltung? Ergebnisse einer Befragung von Produktionsverantwortlichen deutscher Unternehmen, Ulm, Germany: Ingenics AG, 2016.

[13] B. A. Latos, M. Harlacher, M. El-Mahgary, D. Götzelmann, P. M. Przybysz, S. Mütze-Niewöhner, C. Schlick, "Komplexität in Arbeitssystemen: Analyse und Ordnung von Beschreibungsansätzen aus unterschiedlichen Disziplinen" in 63th Frühjahrskongress der Gesellschaft für Arbeitswissenschaft FHNW, Brugg-Windisch, Switzerland, 2017. https://doi.org/10.18154/RWTH-2017-04217

[14] M. Schwemmle, P. Wedde, Digitale Arbeit in Deutschland: Potenziale und Problemlagen, Bonn; Germany: bub Bonner Universitäts-Buchdruckerei, 2012

[15] J. Dalhöfer, M. Prieß, "Führung im Komplexitätsmanagement: Zusammenhang zwischen Komplexität, Motivation und Stress" ZWF Zeitschrift für Wirtschaftlichen Fabrikbetrieb, 107(1-2), 87-93, 2012. https://doi.org/10.3139/104.110666

[16] A. Hoeschen, "Complexity-based distribution of value added in multinational production systems" (Thesis in German) Ph.D. dissertation, RWTH Aachen University, Germany, 2015.

[17] W. ElMaraghy, H. ElMaraghy, T. Tomiyama, L. Monostori, "Complexity in engineering design and manufacturing" CIRP Annals - Manufacturing Technology 61(2), 793-814, 2012. https://doi.org/10.1016/j.cirp.2012.05.001

[18] R. Riedl, Strukturen der Komplexität: Eine Morphologie des Erkennens und Erklärens, Berlin, Germany: Springer, 2000. https://doi.org/10.1007/978-3-642-56946-3

[19] C. Schlick, R. Bruder, H. Luczak, Arbeitswissenschaft, 4th ed., Heidelberg, Germany: Springer, 2018. https://doi.org/10.1007/978-3-662-56037-2

[20] C. R. Shalizi, "Methods and Techniques of Complex Systems Science", In: T. S. Deisboeck, J. Y. Kresh (Ed.) Complex systems science in biomedicine, New York, USA: Springer, 49-131, 2006.

[21] H. A. Simon, The sciences of the artificial, 3rd ed., Cambridge, USA: MIT Press, 1996.

[22] M.-O. Blockus, "Komplexität in Dienstleistungsunternehmen: Komplexitätsformen, Kosten- und Nutzenwirkungen, empirische Befunde und Managementimplikationen”, Ph.D. dissertation, Universität Basel, Switzerland, 2010, 1st ed., Wiesbaden, Germany: Gabler Research, 2010. https://doi.org/10.1007/978-3-8349-8958-1

[23] L. von Bertalanffy, "Vorläufer und Begründer der Systemtheorie" in System Theory Research and Information, (Systemtheorie Forschung und Information), R. Kurzrock, Berlin, Germany: Colloquium-Verlag, 17-28, 1972.

[24] J. B. Rosser, "Computational and Dynamic Complexity in Economics", In: J. B. Rosser (Ed.), Handbook of Research on Complexity, Cheltenham, UK: Edward Elgar Publishing, 2009. https://doi.org/10.4337/9781781952665

[25] G. Schuh, U. Schwenk, Produktkomplexität managen. Strategien, Methoden, Tools, München, Germany: Carl Hanser, 2001.

[26] H. Ulrich, G. J. Probst, Anleitung zum ganzheitlichen Denken und Handeln. Ein Brevier für Führungskräfte, Bern, Switzerland: Haupt, 1988.

[27] A. V. Deshmukh, J. J. Talavage, M. M. Barash, "Complexity in manufacturing systems, Part 1: Analysis of static complexity" IIE Transactions, 30(7), 645-655, 1998.

[28] O. Kuzgunkaya, H. A. ElMaraghy, "Assessing the structural complexity of manufacturing systems configurations" International Journal of Flexible Manufacturing Systems, 18(3), 145-171, 2006.

[29] S. Sivadasan, J. Efstathiou, A. Calinescu, L. H. Huatuco, "Advances on measuring the operational complexity of supplier-customer systems" 


\section{B. A. Latos et al. / Advances in Science, Technology and Engineering Systems Journal Vol. 3, No. 5, 166-185 (2018)}

European Journal of Operational Research, 171(1), 208-226, 2006. https://doi.org/10.1016/j.ejor.2004.08.032

[30] S. Mattsson, P. Gullander, U. Harlin, G. Bäckstrand, Å. Fasth, A. Davidsson, "Testing Complexity Index - a Method for Measuring Perceived Production Complexity" in 45th CIRP Conference on Manufacturing Systems, Athens, Greece, 394-399, 2012. https://doi.org/10.1016/j.procir.2012.07.068

[31] L. Zeltzer, V. Limère, H. van Landeghem, E.-H. Aghezzaf, J. Stahre, "Measuring complexity in mixed-model assembly workstations" International Journal of Production Research, 51(15), 4630-4643, 2013. https://doi.org/10.1080/00207543.2013.783246

[32] D. Dörner, H. W. Kreuzig, F. Reither, T. Stäudel, Lohhausen. Vom Umgang mit Unbestimmtheit und Komplexität, Bern, Switzerland: Hans Huber Verlag, 1983.

[33] D. Dörner, Die Logik des Misslingens, Strategisches Denken in komplexen Situationen, 10th ed., Hamburg, Germany: Rowohlt Verlag, 2011.

[34] A. Kluge, Wissenserwerb für das Steuern komplexer Systeme, Lengerich, Germany: Wolfgang Pabst Science Publishers, 2004.

[35] H. Willke, Systemtheorie 1: Grundlagen, 5th ed., Stuttgart, Germany: UTB, 1996.

[36] N. Luhmann, Soziale Systeme. Grundriß einer allgemeinen Theorie, Frankfurt a. M., Germany: Suhrkamp Verlag, 1987.

[37] W. Rohmert, "Das Belastungs-Beanspruchungs-Konzept" Zeitschrift für Arbeitswissenschaft, 38(4), 193-200, 1984.

[38] H. Luczak, "Untersuchungen informatorischer Belastung und Beanspruchung des Menschen" Fortschrittsberichte der VDI-Zeitschriften, 10(2), Düsseldorf, Germany: VDI-Verlag, 1975.

[39] M. W. McElroy, "Integrating complexity theory, knowledge management and organizational learning" Journal of Knowledge Management, 4 (3), 195-203, 2000. https://doi.org/10.1108/13673270010377652

[40] W. Vogel, R. Lasch, "Complexity drivers in manufacturing companies: A literature review" Logistics Research, 9(1), 1-66, 2016. https://doi.org/10.1007/s12159-016-0152-9, licensed under: http://creativecommons.org/licenses/by/4.0/

[41] K.-P. Schoeneberg, Komplexitätsmanagement in Unternehmen. Herausforderungen im Umgang mit Dynamik, Unsicherheit und Komplexität meistern, Wiesbaden, Germany: Springer Gabler, 2014. https://doi.org/10.1007/978-3-658-01284-7

[42] S. Bednar, V. Modrak, "Mass Customization and its Impact on Assembly Process' Complexity" International Journal for Quality Research, 8(3), 417-430, 2014

[43] N. Asadi M. Jackson, A. Fundin, "Drivers of Complexity in a Flexible Assembly System - A Case Study" Procedia CIRP, 41, 189-194, 2016. https://doi.org/10.1016/j.procir.2015.12.082

[44] N. Asadi, S. Javadi, "Key complexity dimensions in assembly systems with mixed-model assembly lines - a multiple case study" in 5th World Conference on Production and Operations Management, Havana, Kuba, 2016.

[45] S. Mattsson, M. Karlsson, P. Gullander, H. van Landeghem, L. Zeltzer, V. Limère, E.-H. Aghezzaf, "Comparing quantifiable methods to measure complexity in assembly" International Journal of Manufacturing Research, 9(1), 112-130, 2014. https://doi.org/10.1504/IJMR.2014.059602

[46] P. Mayring, Einführung in die qualitative Sozialforschung, 5th ed., Weinheim, Germany: Beltz, 2002.

[47] M. Pfadenhauer, Professionelles Handeln, Wiesbaden, Germany: VS Verlag für Sozialwissenschaften, 2005.

[48] P. Mayring, Qualitative Inhaltsanalyse: Grundlagen und Techniken, Weinheim, Germany: Beltz, 2010.

[49] P. Mayring, Qualitative content analysis: theoretical foundation, basic procedures and software solution. Klagenfurt, Germany: Beltz, 2014.

[50] J. Gläser, G. Laudel, Experteninterviews und qualitative Inhaltsanalyse, 3rd ed., Wiesbaden, Germany: VS Verlag für Sozialwissenschaften, 2009.

[51] A. Petz, "Produktivitätsbewertung und simulationsbasierte Gestaltung von wissensintensiven Dienstleistungen" Ph.D. dissertation, RWTH Aachen University, Germany, 2017. https://doi.org/10.2370/9783844057058

[52] A. Petz, S. Duckwitz, C. Schmalz, "Productivity of Services: An Explorative Study in the Electrical and Chemical Engineering Sector" Amfiteatru Economic, 14(Special No. 6), 635-652, 2012.

[53] S. Duckwitz, A. Petz, C. Schmalz, R. Jahnel, P. Lehmacher, C. M. Schlick, "Dienstleistungsproduktivität aus Unternehmensperspektive - Ergebnisse semistrukturierter Leitfadeninterviews", In: C. M. Schlick, M. Schenk, D. Spath, W. Ganz (Ed.), Produktivitätsmanagement von Dienstleistungen: Modelle, Methoden und Werkzeuge, Berlin, Germany: Springer Vieweg, 13-27, 2016. https://doi.org/10.1007/978-3-642-45071-6

[54] J. Wegge, F. Jungmann, S. C. Liebermann, K.-H. Schmidt, B. C. Ries, "Altersgemischte Teamarbeit kann erfolgreich sein: Empfehlungen für eine ausgewogene betriebliche Altersstruktur" Sozialrecht + Praxis, 7, 433-442, 2011.

[55] M. Högl, "Teamarbeit in innovativen Projekten: Einflussgrößen und Wirkungen” Ph.D. dissertation, Universität Karlsruhe, Germany, 1998.

[56] M. Högl, H. G. Gemünden, "Teamwork Quality and the Success of Innovative Projects: A Theoretical Concept and Empirical Evidence" Organization Science, 12(4), 435-449, 2001. https://doi.org/10.1287/orsc.12.4.435.10635

[57] T.-M. Myskovszky von Myrow, "Teamwork during innovation projects: The effects of diversity, participation, and the organizational context" Ph.D. dissertation, RWTH Aachen University, Germany, 2018.

[58] P. M. Przybysz, "Empirische Untersuchungen der Auswirkung von Altersdiversität in Innovationsteams" Ph.D. dissertation, Ernst-Moritz-ArndtUniversität Greifswald, Germany, 2016.

[59] R. A. Stranzenbach, "Analysis and Design of Group Work in Integrated Production Systems" (text in German) Ph.D. dissertation, RWTH Aachen University, Germany, 2018. in press

[60] S. Tannenbaum, R. Beard, E. Salas, "Team building and its influence on team effectiveness. An examination of conceptual and empirical developments" Advances in Psychology, 82, 117-153, 1992. https://doi.org/10.1016/S0166-4115(08)62601-1

[61] P. Trompisch, "The implications of Industry 4.0 on the future of work" (article in German with an abstract in English) Elektrotechnik \& Informationstechnik 134(7), 370-373, https://doi.org/10.1007/s00502-017-0531-1

[62] J. Rasmussen, A. M. Pejtersen, L. P. Goodstein, Cognitive Systems Engineering, New York, USA: Wiley, 1994.

[63] S. Mattsson, "What is perceived as complex in final assembly? To define, measure and manage production complexity" Ph.D. Thesis, Chalmers University of Technology Gothenburg, Sweden, 2013.

[64] T. Fässberg, U. Harlin, K. Garmer, P. Gullander, Å. Fasth, S. Mattsson, K. Dencker, A. Davidsson, J. Stahre, "An Empirical Study Towards a Definition of Production Complexity" in 21st International Conference on Production Research, Stuttgart, Germany, 2011.

[65] G. Schuh, M. Riesener, Produktkomplexität managen. Strategien -Methoden - Tools, 3rd ed., Munich, Germany: Hanser, 2017. https://doi.org/10.3139/9783446453340

[66] A. Kaiser, "Integriertes Variantenmanagement mit Hilfe der Prozesskostenrechnung” Ph.D. Thesis, University of St. Gallen, Switzerland, 1995.

[67] S. D. Dionne, F. J. Yammarino, L. E. Atwater, W. D. Spangler, "Transformational leadership and team performance" Journal of Organizational Change Management, 17(2), 177-193, 2004. https://doi.org/10.1108/09534810410530601

[68] E. A. Locke, G. P. Latham, A Theory of Goal-Setting and Task Performance, New Jersey, USA: Englewood Cliffs, Prentice Hall, 1990.

[69] EN ISO 9241 Part 110 (September 2008): Ergonomics of human-system interaction - Part 110: Dialogue principles 